\title{
Journey Planning Based on User Needs
}

\section{Paul André}

University of Southampton

School of Electronics and CS

Southampton, SO17 1BJ, UK

pa2@ecs.soton.ac.uk

\section{Max L. Wilson}

University of Southampton

School of Electronics and CS

Southampton, SO17 1BJ, UK

mlw05r@ecs.soton.ac.uk

\section{Alisdair Owens}

University of Southampton

School of Electronics and CS

Southampton, SO17 1BJ, UK

ao@ecs.soton.ac.uk

Daniel Alexander Smith

University of Southampton

School of Electronics and CS

Southampton, SO17 1BJ, UK

das05r@ecs.soton.ac.uk

Copyright is held by the author/owner(s).

CHI 2007, April 28 - May 3, 2007, San Jose, California, USA.

ACM 978-1-59593-642-4/07/0004

\begin{abstract}
In this paper we discuss potential developments to the design of pre-trip in-home journey planning services, to include support for additional user needs. These needs were identified through stakeholder interviews as contributing to actual decisions in route selection scenarios and include: safety, weather and even fitness. A journey planner was designed to allow users to articulate these constraints and a series of paper prototypes were evaluated through cognitive walkthroughs. An exploratory study compared three designs and provided rationale for the most effective interaction method, informing an implementation plan.
\end{abstract}

\section{Keywords}

Public transport, journey planner, exploratory study

\section{ACM Classification Keywords}

H.5.m. Information interfaces and presentation (e.g., HCI): Miscellaneous. H.5.2. User Interfaces: Usercentered design.

\section{Introduction}

Transport is an essential part of our lives, providing access to goods, services, employment and social opportunities. Yet it is plagued with problems: congestion, noise and air pollution, under- or overutilisation of public transport, and land loss to roads to name a few [9]. These issues can be partially solved or alleviated in two ways: (a) making the car a less 
attractive way to travel [12], (b) making public transport a more attractive alternative.

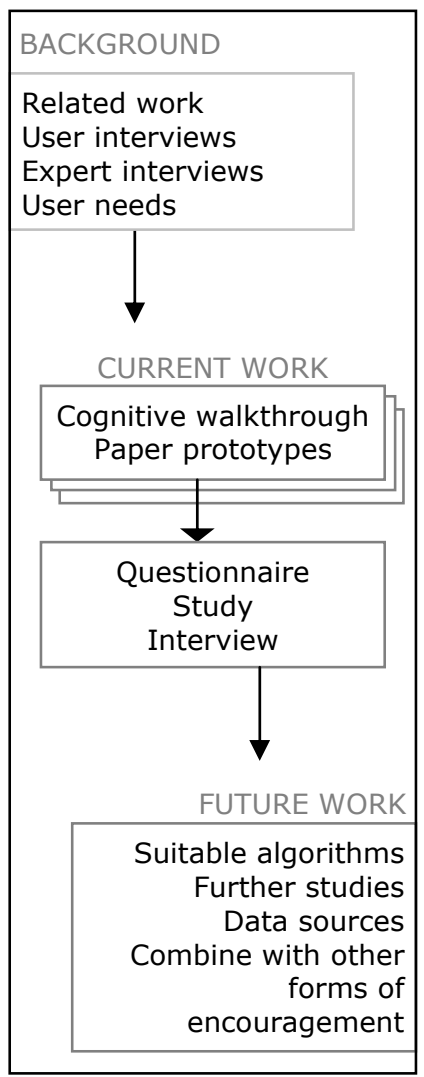

Figure 1. Overview of our design process
In support of the latter goal, a report on the ROMANSE project, which provides real-time travel information, stated that the greatest potential impact on travel behaviour was the provision of "pre-trip in-home information" [7]. Beecroft and McDonald [1] predict a blurring of collective and private forms of travel, occurring in public transport becoming more focused on user needs, with this process supported by route planning. This bespoke approach is echoed by Hoogma et al. [4], with the concept of "the inclusion of all means of transport into an individually tailored package deal in which users determine for every trip which transport modes or combinations of modes best suit their needs".

To support in-home journey planning, we wanted to understand what needs or additional factors users would want to control. This research is directed at car users to convert their journeys to public transport, as well as supporting those who currently use public transport in our local area - nationwide implementation is discussed at the end of the paper. To identify these factors we undertook related research and interviews with end users and domain experts. Scenarios were developed to inform a series of prototypes that extended the functionality of currently available journey planners. The prototypes were evaluated using cognitive walkthroughs. Finally, three distinct interaction metaphors were compared in an exploratory study to answer two research goals: a) Whether providing control over user-identified needs encourages increased use of public transport.

b) What interaction method increases the effectiveness of such control.

The focus of this work is to encourage public transport use through addressing personal planning constraints, and we propose the investigation of algorithms and data sources in subsequent future work.

\section{Design Process}

Following the design process in Fig. 1, we began with a series of semi-structured interviews with domain experts including the Director of the Transport Research Group (TRG) at the University of Southampton. This was supported by interviews with key academic and commercial partners of the nationwide sustainable transport research project: FUTURES. Interviews were also conducted with a marketing director for transport organisations and the head of transport for a local bus service. These interviews highlighted the need to extend current schedule and cost information with consumer concerns and contextual information to make public transport as seamless as car use, and increase comfort and reassurance in changing travel patterns.

\section{Related Work}

The Verkehrsverbund system [8], which organises regional public transport in Germany, attributes its success to physical attributes: service expansion, better quality service, better marketing, and a uniform, integrated fare structure. A study on the doubling of patronage of public transport in Freiburg [3] found the main explanation for the increase was a low cost travel 


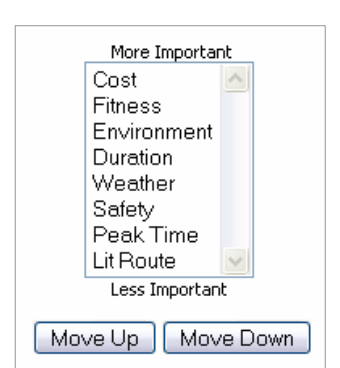

Figure 3. The control to rank the factors.

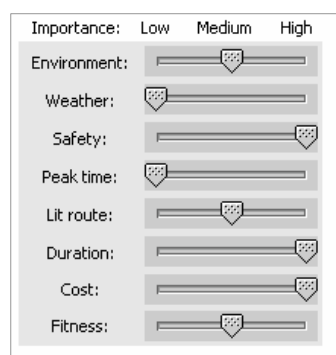

Figure 4. The control to rank each factor low, medium, or high.

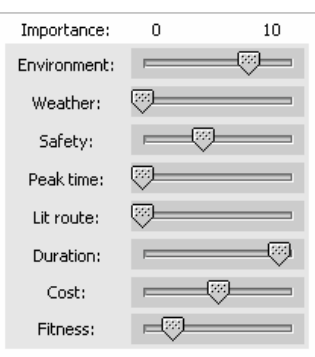

Figure 5. The control to rank each factor from 0 to 10. metaphor, prioritisation through ranking has been used in Fig. 3.

\section{Study \\ Aims}

This exploratory study was designed to investigate our two research goals: to see if providing control over user-identified needs would encourage increased use of public transport, and what method of control achieves this goal.

\section{Design}

The following user needs were identified through our interviews and related work:

Environment: Using a carbon footprint ${ }^{2}$. A user can express a wish for reducing environmental damage. Weather: A user can express a wish to avoid bad weather.

Safety: A user can express a wish to avoid areas known as posing a risk of criminal activity.

Peak Travel: A user can express a wish to avoid busy public transport at peak times.

Lighting: A user can express a wish to avoid unlit areas, such as parks or roads without street-lighting. Duration: A user can express a wish to be in travel for as little time as possible.

Cost: A user can express a wish to travel for as little money as possible. (Car costs based on average running costs $^{3}$ ).

Fitness: A user can express a wish for exercise opportunities, such as walking.

\footnotetext{
${ }^{2}$ http://www.carbonfootprint.com/calculator.html
}

${ }^{3}$ http://news.bbc.co.uk/1/hi/uk/6068568.stm
Participants were given a generic scenario (based on a real route) so that prior knowledge was not a confounding variable. The scenario provided opportunity for each variable to be applied, covering for example: darkness, rain, unlit areas and peak travel.

\section{Methodology}

12 participants were chosen, varying in age, gender, education and existing use of public transport. A within subjects evaluation was performed over the three designs; the order of exposure was rotated. Each user was asked to read the scenario carefully and choose a route with each interface in the appropriate order. Timing and preference were measured. Users were asked to think aloud while choosing each route. Prestudy questionnaires and semi-structured follow-up interviews were carried out.

\section{Results}

The pre-study questionnaire showed that of the 12 participants ( 7 male, 5 female), 6 owned a car, and public transport usage ranged from daily to monthly or less. All participants expressed an interest in the concept and would like to investigate it further, and $50 \%$ of car users said that given this extra control over their journey, they would be tempted to switch some of their car journeys to public transport.

The second goal of the study was to look at the preferred method of expressing control. Results across the three interfaces were mixed. There was no significant trend towards a particular interface either by time or preference. Further investigation, through chisquared analysis, revealed the following: 
- The average time spent on each interface varied between participants but not within participants.

- Men spent significantly more than 90 seconds choosing a route and women less $\left(X^{2}(1, N=12)=6.12, p<=0.025\right)$.

- Women had a significant preference for the Lo-Hi interface $\left(X^{2}(4, N=12)=12, p<=0.025\right)$. Men, however, had a mixed view that tended toward ranking, or $0-10$.

- $\quad$ Car owners preferred 0-10 $\left(X^{2}(4, N=12)=8.57\right.$, $\mathrm{p}<=0.1$ ), and ranking was almost consistently rejected. For non car-owners, preference was mixed.

No correlations were discovered between regular and infrequent users of public transport. Similarly there was no correlation across age, education or experience with journey planning software.

\section{Discussion}

The results of the study and interviews were promising, with one participant stating "sometimes a site gives me routes, and I think, 'that one's not safe', but I can't tell the site that", pleased that they were able to express control over such factors.

The results of the interface preference are hard to apply. While it appears men prefer ranking or $0-10$, they statistically spent more time playing with all three versions. This indicates they tend to prefer tools that allow for investigation. However, while women statistically preferred Lo-Hi, 0-10 was a close second, with ranking near uniformly rejected - tending towards finer-grained control. The near significant preference of car-owners towards increased control over their priorities provides an interesting insight for a suggested design choice. Follow-up discussions indicate that route-planning outside of normal routine provides the occasion to prioritise travel needs. Car-owners would naturally use a car for such a journey. Those without access to a car have to plan a new route and prioritise their needs. As the preference of car-less participants was mixed and it was the preference of car owners to have more control, the 0-10 design may encourage car-owners to use public transport.

This analysis suggests that the 0-10 interface be implemented. While male and car-less participants do not have a clear preference, women tended towards finer-grained control. Also, car-owners who are less familiar with prioritizing their transport needs tended towards investigative control, which suggests that $0-10$ may be the best design for encouraging the use of public transport. It may be worth noting that the majority of females prioritized safety and lit routes during the study, which indicates that such controls may encourage women to use public transport.

Users who did not prefer the 0-10 interface generally had one of two criticisms: either it was hard to assign a number to how important something was, or that there were too many options, and even leaving the sliders at 0 still felt overwhelming. By labelling the extremes "No Importance / Very Important", and allowing users to select which sliders to use (perhaps greying-out the others), we hope to address these issues.

\section{Implementation}

To implement our design concept, a web service is required to take a route and give it a rating for each constraint. While our scenario used pre-determined routes, we have identified data sources, in collaboration 
with the Transport Research Group, to support the attributes for route selection. For example, local government bodies have records of every streetlamp, weather forecasts are available online, and the police have crime statistics. Additionally, strategies for helping users to contribute their feedback on route segments will support an evolving community environment. Previous experience with heterogeneous data linking, through the Advanced Knowledge Technologies research initiative ${ }^{4}$, indicates that these data integration issues are tractable.

\section{Conclusions}

From related research it is clear there is a call for public transport information based on user needs, and through an iterative user-centred design process we have developed a journey planner allowing users to express control over a number of constraints identified through interviews. All study participants were enthusiastic about the concept, and $50 \%$ of car users said that given this extra control over their journey, they would be tempted to switch some of their car journeys to public transport. Analysis of user preference between designs indicated a preference for articulating constraints by assigning a $0-10$ rating. Finally, we discuss methods for implementing this design towards making public transport a more accessible option.

\section{Acknowledgements}

We thank Mike McDonald, Mark Beecroft, Alec Gore and Ray Stenning for their expert insight, m.c. schraefel as our team mentor, and the participants in our studies.

\footnotetext{
${ }^{4}$ http://www.aktors.org/akt/
}

\section{References}

[1] Beecroft, M., McDonald, M. Bespoke services for personal travel and goods movement. Engineering Sustainability, 158(2), (2005), 83-88.

[2] Edvardsson, B. Causes of customer dissatisfaction - studies of public transport by the critical-incident method, Managing Service Quality 8(3) (1998) 189-97.

[3] Fitzroy, F., Smith, I. Public transport demand in Freiburg: why did patronage double in a decade? Transport Policy, 5(3), (1998), 163-173.

[4] Hoogma, R., et al. Experimenting for sustainable transport. The approach of strategic niche management. Spon Press, London, 2002.

[5] McGinty, L.,Smyth, B. Personalised Route Planning: A Case-Based Approach. EWCBR 2000, 431-442.

[6] O'Sullivan, D., et al. Using desktop GIS for the investigation of accessibility by public transport: An isochrone approach, International Journal of Geographical Information Science, 14, (2000) 85-104.

[7] Powell, R. et al. "Real time passenger information system for the ROMANSE project," Public Transport Information and Management Systems, IEE Colloquium on, 9/1-9/4, 1993.

[8] Pucher, J., Kurth, S. Verkehrsverbund: the success of regional public transport in Germany, Austria and Switzerland, Transport Policy, 2(4), (1996) 279-291.

[9] Rodrigue, J-P et al. The Geography of Transport Systems, Hofstra University, Dept. of Economics \& Geography, (2006) http://people.hofstra.edu/geotrans.

[10] Stradling, S.G. Transport user needs and marketing public transport. Municipal Engineer: Special Issue on Sustainable Transport Policy. 151, (2002), 23-28.

[11] Transport Direct Information, see http://www.transportdirect.gov.uk

[12] Wright, C. \& Egan, J. De-marketing The Car. Transport Policy, 7, (2000), 287-294. 